\title{
Dengue Induced Syndrome of Inappropriate Secretion of Anti-Diuretic Hormone
}

\author{
Andrew S Miller ${ }^{1 *}$, Alexa C Wonnacott ${ }^{2}$ and John W McBride ${ }^{3}$ \\ ${ }^{1}$ Emergency Department Resident Medical Officer, Cairns Base Hospital Emergency Department, Cairns, Queensland, Cairns Base Hospital, Esplanade, Cairns City, \\ Queensland, 4870. \\ ${ }^{2}$ Emergency Department Resident Medical Officer, Cairns Base Hospital Emergency Department, Cairns, Queensland, Cairns Base Hospital, Esplanade, Cairns City, \\ Queensland, 4870. \\ ${ }^{3}$ Consultant Microbiologist, Cairns Base Hospital Infectious Diseases Department, Cairns, Queensland, \\ Cairns Base Hospital, Esplanade, Cairns City, Queensland, 4870
}

\section{Introduction}

The dengue virus is an RNA virus isolated to the tropics; 35 degrees from the equator. It is considered to be one of the most important arboviral infections to affect humans, with more than 100 million cases of dengue fever documented annually worldwide.

Dengue epidemics occur frequently in north Queensland, although the virus is not endemic to the region. Epidemics are initiated by viraemic travellers arriving from dengue-affected countries and spread by the native Aedes Mosquito. More than 800 cases of dengue occurred during this wet season, with all four serotypes of the disease identified. One dengue-associated death was recorded during this period in north Queensland. Despite the close proximity to the South Pacific islands, the majority (57\%) of laboratory confirmed importations during 2009 were from South East Asia [1].

The typical features of dengue fever include headache, arthralgia (break-bone fever), vomiting, fever, thrombocytopenia and elevated liver enzymes. A typical fine measles like rash with occasional petechial spots is classical and can be precipitated with a tourniquet test.

Dengue haemorrhagic fever most commonly occurs in children under the age of 15 and adults who have previously been exposed to a different serotype of the virus. Infection results in increased vascular permeability with subsequent plasma volume loss and haemoconcentration. Patients develop haemostatic defects as a consequence of thrombocytopenia, platelet dysfunction and coagulopathy. Non haemorrhagic neurological involvement is rare but has also been noted. The exact aetiology of this remains unclear.

\section{Clinical Record}

A 47 year-old female, who was previously fit and well, presented to the Emergency Department with intermittent agitation associated with a fluctuating level of consciousness. She was noted to have slurred speech but was able to obey simple commands. Further history was available from her partner who stated that for the preceding 4 days she had complained of nausea, headaches and persistent arthralgia. She had visited her general practitioner the morning before her presentation, who had made a clinical diagnosis of dengue fever. She had no previous medical history other than possible dengue fever as a child whilst living in Singapore. Unfortunately, no medical documentation was available to confirm this or identify a serotype.

Initial haemodynamic observations were within normal parameters with the exception of low grade pyrexia of $37.6^{\circ} \mathrm{C}$. She was obtunded with a variable GCS of 10 to 13 . On examination her pupils were reactive to light and accommodation and nystagmus on lateral gaze noted. The remainder of the neurological examination was normal. Her cardiovascular, respiratory and abdominal examinations were all unremarkable and there was no visible rash. Initial clinical assessment of volume status deemed the patient to be adequately hydrated with a urine output of greater than $30 \mathrm{ml} / \mathrm{min}$. She was noted to bleed excessively from her cannula site.

Initial biochemical investigations revealed a serum sodium of 113 $\mathrm{mmol} / \mathrm{L}$ (137-147), raised aspartate transaminase (AST) $115 \mathrm{U} / \mathrm{L}(0$ 41 ) and total bilirubin of $22 \mu \mathrm{mol} / \mathrm{L}$ (NR). The haematocrit was 0.46 and a reduced platelet count $74 \times 10^{9} / \mathrm{L}$ was noted (Table 1 ). Contrast and non-contrast computerised tomography were undertaken, reported as showing very mild cerebral oedema with slight effacement of the ventricles. Electrocardiography and chest $\mathrm{x}$-ray were both normal.

The patient was sedated and intubated due to ensuing encephalopathy and admitted to the intensive care ward. Lumbar puncture was contraindicated at this time owing to the thrombocytopenia, clinical coagulopathy and the possibility of raised intracranial pressure. She was initially treated with empirical aciclovir and ceftriaxone to cover the possibility of meningococcal or Herpes Simplex virus infection. Cautious sodium replacement was undertaken using hypertonic $3 \%$ saline solution at an initial rate of $30-40 \mathrm{ml} / \mathrm{hr}$, thus ensuring that the serum sodium did not increase by greater than $10 \mathrm{mmol}$ in the first 24 hours.

Initial serology results from the local medical officer were positive for dengue IgG and negative for IgM (Table 1) suggesting a secondary dengue infection. Direct NS1 antigen testing for Dengue was positive. Ross river and Barmah forest serology were negative.

A diagnosis of Dengue haemorrhagic fever was made due to the presence of persistent fever $\left(37.6\right.$ to $38^{\circ} \mathrm{C}$ ), haematocrit concentration ( 0.37 to 0.46$)$, thrombocytopenia and a bleeding disorder. She was also felt to have syndrome of inappropriate secretion of anti-diuretic hormone (SIADH), as she maintained a high urine sodium $(77 \mathrm{mmol} / \mathrm{L})$ and osmolality $(513 \mathrm{mmol} / \mathrm{Kg})$ despite a low plasma osmolality $(240 \mathrm{mmol} / \mathrm{Kg})[9]$ in the presence of normal renal, adrenal and thyroid function.

*Corresponding author: Andrew S Miller, Emergency Department Resident Medical Officer, Cairns Base Hospital Emergency Department, Cairns, Queensland, Cairns Base Hospital, Esplanade, Cairns City, Queensland, 4870, E-mail: Milleras@cf.ac.uk

Received November 02, 2011; Accepted January 06, 2012; Published January 13,2012

Citation: Miller AS, Wonnacott AC, McBride JW (2012) Dengue Induced Syndrome of Inappropriate Secretion of Anti-Diuretic Hormone. J Clinic Case Reports 2:109. doi:10.4172/2165-7920.1000109

Copyright: (C) 2012 Miller AS, et al. This is an open-access article distributed under the terms of the Creative Commons Attribution License, which permits unrestricted use, distribution, and reproduction in any medium, provided the original author and source are credited. 


\begin{tabular}{|c|c|c|c|c|c|c|c|}
\hline \multirow[b]{2}{*}{ Serum Biochemistry } & \multicolumn{2}{|c|}{ Day of Illness } & \multirow[b]{2}{*}{5} & \multirow[b]{2}{*}{6} & \multirow[b]{2}{*}{7} & \multirow[b]{2}{*}{8} & \multirow[b]{2}{*}{10} \\
\hline & 3 & 4 (Admitted) & & & & & \\
\hline Sodium (mmol/L) & 125 & 113 & 122 & 133 & 135 & 136 & 138 \\
\hline Potassium (mmol/L) & 3.7 & 3.8 & 4.1 & 4.3 & 4.2 & 3.6 & 3.5 \\
\hline Urea (mmol/L) & 2.5 & 3.3 & 3.4 & 2.1 & 2.1 & 1.8 & 3.0 \\
\hline Creatinine $(\mu \mathrm{mol} / \mathrm{L})$ & 53 & 53 & 43 & 32 & 32 & 36 & 38 \\
\hline Osmolality (mmol/kg) & & 240 & & & 276 & & \\
\hline Uric Acid (mmol/L) & 0.09 & & & & 0.06 & & \\
\hline Corrected Calcium (mmol/L) & 2.21 & 2.21 & 2.17 & 2.23 & 2.27 & 2.29 & \\
\hline Haemoglobin (g/L) & 125 & 161 & 134 & 114 & 109 & 106 & 104 \\
\hline Haematocrit & 0.37 & 0.46 & 0.40 & 0.33 & 0.32 & 0.31 & 0.30 \\
\hline White Blood Cells (x109/L) & 3.1 & 4.2 & 6.3 & 3.2 & 2.0 & 5.5 & 5.1 \\
\hline Platelets (x109/L) & 148 & 74 & 76 & 41 & 28 & 133 & 225 \\
\hline \multicolumn{8}{|l|}{ Dengue Serology (positive) } \\
\hline & $\lg G$ & & NS1 & & $\lg M$ & & \\
\hline Urine Biochemistry Sodium (mmol/L) & & 77 & & & & & \\
\hline Potassium (mmol/L) & & 44 & & & & & \\
\hline Creatinine (mmol/L) & & 4.3 & & & & & \\
\hline Osmolarity (mmol/Kg) & & 513 & & & & & \\
\hline
\end{tabular}

Table 1: Biochemistry results during illness.

The patient was successfully extubated 3 days post admission, once the sodium levels had normalised. She was discharged 6 days post admission with outpatient follow up. She sustained no residual neurological defect and is well to date [8].

\section{Discussion}

Dengue virus has long been regarded as a non-neurotropic virus [2] and animal studies have confirmed that the dengue virus is unable to cross the blood brain barrier [3]. Involvement of the central nervous system may be secondary to microcapillary fluid extravasation, cerebral oedema, hypoperfusion, hyponatraemia, liver failure and renal failure. Despite this there have been many reports of encephalopathy associated with the dengue virus where no metabolic cause can be found [4,5]. There are also reports of the dengue virus being isolated from the CSF of infected patients [5].

Hyponatremia is commonly found in association with dengue fever and is thought to be caused by peripheral fluid extravasation and resulting intravascular hypovolaemia. Previous studies have identified that Dengue patients are 9.7 times more likely to have clinically significant hyponatremia $(\mathrm{Na}<130 \mathrm{mmol} / \mathrm{L})$ than patients with similar febrile illnesses. Hypovolaemia, confirmed by a urine sodium of $<20 \mathrm{mmol} / \mathrm{L}$, was also found to be 8.1 times more common in dengue patients [6]. Patients who present with dengue associated hyponatremia with a normal or elevated urine sodium have been hypothesised to have transient syndrome of inappropriate secretion of anti-diuretic hormone, but this has not been conclusively demonstrated.

Interestingly, this patient met all criteria for both dengue haemorrhagic fever [7] and syndrome of inappropriate secretion of anti-diuretic hormone [9] (see appendix).

Despite this, controversy remains as to whether this was, in fact, a true case of SIADH. Physiological teaching suggests that anti-diuretic hormone release is controlled by both osmoreceptors and baroreceptors. Hypothalamic osmoreceptors are extremely sensitive and respond to as little as $1 \%$ variation in tonicity whereas baroreceptors are much less sensitive but far more potent stimulators of ADH release. This means that in the shocked patient, a hypovolaemic stimulus will override a hypotonic inhibition and volume will be conserved at the expense of tonicity [10]. This mechanism would account for the rapid fall in sodium levels while the patient was symptomatic, whilst microcapillary leakage could explain the preceding hyponatraemia. However, this patient was clinically euvolaemic and haemodynamically stable with normal central venous pressures throughout her hospitalisation, further supporting a diagnosis of SIADH.

The management of this case required careful consideration. Inappropriate antidiuretic hormone initially causes an increase in water retention followed by a secondary solute loss mediated by a normal renin-angiotensin-aldosterone system. Providing excess salt is not lost from another source, such as the gastrointestinal tract or from cerebral salt wasting, the patient's intravascular volume is maintained. Treatment therefore involves fluid restriction to create a negative balance in order to restore osmolality. However, in this patient with haemorrhagic fever, ongoing capillary leakage coupled with fluid restriction would have precipitated worsening intravascular hypovolaemia. The decision was made to treat her with $3 \%$ hypertonic saline to maintain perfusion pressures and prevent further hyponatraemia- induced cerebral oedema. A regime of low volume, hypertonic saline resuscitation was used with a rate of correction of less than $10 \mathrm{mmol}$ over the first 24 hours to avoid osmotic demyelination.

To our knowledge, this report describes the first case of SIADH caused by dengue haemorrhagic fever and highlights the association of hyponatraemia with the dengue virus. Prompt diagnosis and vigilant fluid resuscitation may help to reduce the incidence of neurological complications of the dengue infection.

\section{References}

1. Hanna JN, Richards AR, Esmonde JV, Donohue S, Humphreys JL, et al. (2010) Viraemic importations of dengue into north Queensland, 2009 Queensland Health Report. Commun Dis Intell 34: 57-58. 
Citation: Miller AS, Wonnacott AC, McBride JW (2012) Dengue Induced Syndrome of Inappropriate Secretion of Anti-Diuretic Hormone. J Clinic Case Reports 2:109. doi:10.4172/2165-7920.1000109

2. Brinton MA, McKendall RR, Stoop WG (1994) Editors Handbook of neurovirology. 379-389.

3. Nathanson N, Cole GA (1970) Immunosuppression and experimental virus injection of the nervous system. Adv Virus Res 16: 397-428.

4. Misra UK, Kalita J, Syam UK, Dhole TN (2006) Neurological manifestations of dengue virus infection. J Neurol Sci 244: 117-122.

5. Lum LCS, LAM SK, Choy YS, George R, Harun F (1996) Dengue Encephalopathy: A True entity? Am J Trop Med Hyg 54: 256-259.

6. Mekmullica J, Suwanphatra A, Thienpaitoon H, Chansongsakul T, Cherdkiatkul T, et al. (2005) Serum and Urine Sodium levels in dengue patients. Southeast Asian J Trop Med Public Health 36: 197-199.

7. WHO (1997) Dengue haemorrhagic fever: diagnosis, treatment, prevention, and control. 2nd ed. Geneva: World Health Organization.

8. Solomon T, Dung NM, Vaughn DW, Kneen R, Thao LT, et al. (2000) Neurological manifestations of dengue infection. Lancet 355: 1053-1059.

9. Burton D Rose (2008) Diagnosis of hyponatremia. Up-To-Date Last literature review version 16.3: October 2008 UTDOL.com

10. Kerry Brandis (1997) Fluid and Electrolyte Physiology. Gold Coast Hospital Anaesthetic revision guide.

\section{Appendix}

Biochemical diagnosis of dengue Haemorrhagic Fever [7]

Febrile $\left(37.6-38^{\circ} \mathrm{C}\right)$

$20 \%$ Increase in Haematocrit (0.37 to 0.46$)$

Thrombocytopenia (PIt 76)

Petechiae/ Bleeding disorder (bleeding from cannula site)

Biochemical diagnosis of SIADH [9]

low plasma osmolality $(240 \mathrm{mmol} / \mathrm{Kg})$

Elevated urine osmolality $>300 \mathrm{mosmol} / \mathrm{kg}(513 \mathrm{mmol} / \mathrm{Kg})$

A urine sodium concentration $>40 \mathrm{mmol} / \mathrm{L}(77 \mathrm{mmol} / \mathrm{L})$

Low serum uric acid concentration $(0.09 \mathrm{mmol} / \mathrm{L})$

A relatively normal plasma creatinine concentration $(53 \mu \mathrm{mol} / \mathrm{L})$

Normal acid-base and potassium balance (normal)

Normal adrenal and thyroid function (normal)

Note: Patients results in Brackets 